\title{
The Nature of Inhibitory Activity by Staphylococcus aureus Type 71
}

\author{
By G. I. BARROW \\ Public Health Laboratory, Bradford
}

(Received 10 January 1963)

\begin{abstract}
SUMMARY
Antibiotic production in liquid media by Staphylococcus aureus strains of bacteriophage 'type 71 ' was poor as measured by cup assays against susceptible corynebacteria. Aerobic incubation in freshly prepared tryptic-digest broth containing a fermentable carbohydrate and adjusted to $\mathrm{pH} 7 \cdot 8$ gave the greatest yields. The antibiotic material was not obtained in a pure state, but was concentrated by evaporation of crude solutions. These were prepared by adding trichloroacetic acid to broth cultures and centrifuging to remove the organisms. The antibiotic was stable and relatively heat-resistant under acid conditions, but was rapidly destroyed when alkaline; it diffused slowly through cellophan, was adsorbed by charcoal, and was inactivated by trypsin but not by pepsin. These properties suggest that it may be protein or polypeptide in nature. Inhibitory activity by type 71 cocci was shown in mixed broth cultures against other noninhibitory strains of Staphylococcus aureus, and was similar to that previously observed on solid media.
\end{abstract}

\section{INTRODUCTION}

Staphylococcus aureus strains of bacteriophage 'type $7 \mathbf{1}$ ' are frequently isolated from superficial infections of the skin (Barrow, 1955; Parker, Tomlinson \& Williams, 1955). They produce sharply defined inhibition zones in direct antagonism tests against corynebacteria on solid media (Parker, 1958). In deferred antagonism experiments, Parker \& Simmons (1959) also observed weak activity against other strains of Staphylococcus aureus, but failure to obtain active bacteria-free preparations from cultures grown either in liquid or on solid media restricted their investigation of the antagonistic agent. Later, type 71 organisms were found to be strongly and directly active on solid media against most other Staphylococcus aureus strains, as well as against many other Gram-positive species (Barrow, 1963). The present paper concerns further observations on the nature and properties of the inhibitory agent produced by type 71 staphylococci in liquid media.

\section{METHODS}

Organisms. These were described previously (Barrow, 1963). They included: two indicator corynebacteria (an unnamed diphtheroid organism 'Bradford' and an avirulent strain of Corynebacterium diphtheriae type mitis 'Manchester') which are susceptible to inhibition by active (DI +) staphylococci; seven DI + strains of Staphylococcus aureus type 71, which give sharply defined inhibition zones with the 
corynebacteria; two DI + aureus strains from the National Collection of Type Cultures (NCTC 6507, NCTC 8004) which produce hazy zones of inhibition with the Manchester corynebacterium. The two indicator corynebacteria were used in parallel; one of the type 71 strains was used extensively, but confirmatory tests were made with the others. Strains of Staphylococcus aureus not active against corynebacteria (DI -) were also employed in some experiments, and as indicator organisms in assays of type 71 material.

Medium. Suitable broth was important for detectable antibiotic production by type 71 staphylococci. Horse-flesh trypsin-digest broth, with the addition of $0.002 \%(\mathrm{w} / \mathrm{v})$ cystine hydrochloride, was usually satisfactory for this purpose. Incubation was aerobic at $37^{\circ}$ overnight, unless otherwise stated.

Assay methods. The methods used to obtain active bacteria-free material are described later. These preparations were assayed for inhibitory activity against corynebacteria and DI - staphylococci as follows.

(i) Agar-cup method. Blood agar medium in Petri dishes was seeded with broth suspensions of indicator organisms. When dry, cups $8.0 \mathrm{~mm}$. in diameter were punched out, and without sealing, were filled with twofold dilutions of the assay material made in quarter-strength Ringer solution. After incubation, the width of any inhibition zone was recorded. This method was sufficiently accurate for comparative purposes.

(ii) Dilution method. Dilutions, ranging from $10^{-1}$ to $10^{-6}$, were made from a broth culture of a staphylococcal strain known to be inhibited on solid media by type 71 organisms. Equal quantities (usually $1.0 \mathrm{ml}$.) of normal broth and of the material to be assayed were distributed in two sets of sterile tubes. A standard volume $(0.02 \mathrm{ml}$.) of each culture dilution was then dropped into one tube of each set. Readings were made after incubation at $37^{\circ}$ for 24 and $48 \mathrm{hr}$. The end-point was taken as the largest inoculum which gave no visible growth in the assay material, but visible growth in the corresponding control tube.

\section{RESULTS}

\section{Production of antibiotic in liquid media}

Antibiotic material. Preliminary attempts to detect activity against corynebacteria in cup assays of type 71 broth culture preparations were equivocal, partly because of low titres and partly because of difficulty in obtaining suitable material. Broth cultures passed through Seitz or sintered glass filters were inactive, and repeated centrifugation seldom yielded a sterile supernatant fluid. The following methods were found useful.

Cellophan-sac cultures. A piece of washed cellophan (Visking) tubing was tied at the ends to inlet and outlet tubes in the stopper of a conical filtration flask, the loop of tubing so formed was covered with broth, and the flask autoclaved. When cool, the cellophan loop was filled with sterile broth through the inlet tube and then inoculated with type 71 organisms. On incubation, growth occurred inside the tubing; the broth outside remained sterile and was found to have inhibitory activity against corynebacteria. Controls, obtained similarly after growth of noninhibitory staphylococci, were inactive.

Heat treatment. The inhibitory agent in broth cultures withstood a considerable 
degree of heating without much loss of inhibitory activity. Usually cultures were placed in boiling water for a few minutes, sufficient to kill all the organisms, and then cooled rapidly by immersion in cold water. After centrifugation the supernatant fluid was removed and was active in cup assays against corynebacteria.

Acid treatment. The inhibitory agent was retained in solution after precipitation of the organisms and proteins in broth cultures by the addition of an equal volume of $10 \%(\mathrm{w} / \mathrm{v})$ trichloroacetic acid. After centrifugation, the supernatant fluid was carefully neutralized with $5 \mathrm{~N}-\mathrm{NaOH}$ (phenol red as indicator) and showed antibiotic activity, whereas cultures of non-inhibitory staphylococci, treated in the same way, gave inactive fluids. Although diluted twofold, this material usually gave inhibition titres in cup assays against corynebacteria similar to those of the undiluted preparations obtained from cellophan-sac or heated cultures. Material prepared by acid treatment was therefore mainly used.

Conditions for antibiotic production. Preliminary work suggested that broths varied considerably in their ability to allow detectable antibiotic production by type 71 staphylococci. Different broths, including meat infusions and digests, Lemco broth, casein and lactalbumin hydrolysate media, and several commercial products, were therefore compared. Cup assays of the crude solutions against corynebacteria indicated that broth freshly prepared by tryptic digestion of meat usually gave the greatest yields; many of the others showed no inhibitory activity at all. Variation was, however, observed between different batches of digest broth, and deterioration also occurred during prolonged storage. The addition of glucose or mannitol, and an initial $\mathrm{pH}$ of about $7 \cdot 8$, appreciably increased the antibiotic titre. This was highest after aerobic incubation at $37^{\circ}$, and was directly related to the amount of growth. Maximum activity was reached within $24 \mathrm{hr}$., after which the titre slowly fell. Under these conditions, the highest titre obtained in cup assays against corynebacteria was $\mathrm{I}$ in 128. Decreased $\mathrm{O}_{2}$ or increased $\mathrm{CO}_{2}$ tension made little difference; anaerobic incubation was unsatisfactory. Shallow and deep cultures, with and without intermittent shaking, all gave similar results. Screwcapped containers filled with digest broth were therefore used for growth of type 71 organisms.

Concentration of the antibiotic agent. Extraction, or filtration, of the inhibitory substance from crude broth preparations was unsuccessful. The addition of alkali, $\mathrm{HCl}$, glacial acetic acid and concentrated trichloroacetic acid in the cold resulted in loss of activity. Separation was not obtained with organic solvents, including methanol, ethanol, chloroform, ether, pyridine. Adsorption with activated charcoal removed the activity from solution, but all attempts at subsequent elution failed. Doubtful activity was found in the precipitate given by the addition of an equal volume of saturated $\left(\mathrm{NH}_{4}\right)_{2} \mathrm{SO}_{4}$ solution. Considerable activity was, however, present in the neutralized supernatant fluid obtained after precipitation of organisms and proteins from broth cultures with an equal volume of $10 \%(\mathrm{w} / \mathrm{v})$ trichloroacetic acid. No activity was detected in the residue from this culture supernatant fluid after evaporation to dryness, nor did re-inoculation of the supernatant fluid with type 71 organisms enhance the inhibitory activity. The antibiotic material was concentrated by evaporating the neutralized trichloroacetic acid fluid supernatant in Visking tubing in a current of warm air to about one-eighth of its volume. This gave a copious inactive deposit which was removed by centrifugation. After 
dialysis, the residual fluid contained about four times the activity of the original culture preparation against corynebacteria, and in cup assays it also produced weak inhibition of DI - staphylococci.

\section{Properties of the antibiotic material}

Stability. Concentrated antibiotic preparations, adjusted to $\mathrm{pH} \mathbf{3} \cdot \mathbf{0}, \mathbf{7} \cdot \mathbf{0}$ and $8 \cdot \mathbf{5}$, were assayed against corynebacteria after heating at $(a) 60^{\circ}$ for $1 \mathrm{hr}$., $(b) 100^{\circ}$ for $15 \mathrm{~min} .,(c) 120^{\circ}$ for $15 \mathrm{~min}$. in the autoclave. Under neutral and acid conditions, the inhibitory activity remained substantially the same after heating at $60^{\circ}$, slight loss occurred at $100^{\circ}$, and complete loss occurred after autoclaving. In alkaline solution the activity was rapidly destroyed by any form of heating; gradual loss occurred at room temperature (about $18^{\circ}$ ) and at $4^{\circ}$, or after long periods at $-40^{\circ}$. Care was therefore necessary when neutralizing crude material. Under acid conditions, the antibiotic activity was stable at low temperatures.

Dialysis. Crude antibiotic material from heated cultures was placed in cellophan bags made from washed Visking tubing. These were immersed in an equal volume of water or saline and kept at $4^{\circ}$. Material from inside and outside some of the bags was assayed each day for several days, but no evidence of diffusion was observed. However, when unheated concentrated trichloroacetic acid preparations were similarly tested, slow passage of the antibiotic through the cellophan was found.

Susceptibility to enzyme digestion. Equal amounts of sterile enzyme solutions $(1 \%, \mathrm{w} / \mathrm{v}$, in physiological saline) were added to concentrated antibiotic material in tubes, and adjusted to $\mathrm{pH} \mathrm{3.0}$ for pepsin (British Drug Houses 1:2500) and $\mathrm{pH} 8.0$ for trypsin (Difco $1: 250$ ). The tubes were incubated at $37^{\circ}$ in a water bath for $1 \mathrm{hr}$., the solutions neutralized and assayed in cups for activity against corynebacteria. Controls similarly tested included the same antibiotic material $(a)$ with the addition of saline instead of enzymes, $(b)$ with the addition of heat-denatured enzymes, $(c)$ without $\mathrm{pH}$ adjustment. The results showed that inhibitory activity was completely destroyed in $1 \mathrm{hr}$. by trypsin, but was only slightly decreased by pepsin.

\section{Antibiotic activity in mixed broth cultures}

Although inhibitory activity against corynebacteria was readily detected in cup assays of type $7 \mathbf{1}$ digest broth preparations, little was found against DI - staphylococci. Dilution assays were therefore used to try to show such activity. With crude antibiotic preparations, the growth of the corynebacteria was completely suppressed, no matter how large the inoculum, but difficulties were experienced with staphylococci because of inhibition of some type 71 control inocula in the antibiotic material, and the frequent failure of small staphylococcal inocula to grow in normal broth. Some satisfactory results were, however, obtained (Table 1), indicating partial inhibition of DI - staphylococci after overnight culture, but growth usually occurred on further incubation.

Because of these difficulties with dilution assays, mixed broth cultures were examined for inhibitory activity against DI - staphylococci. For this purpose, a DI - strain of Staphylococcus aureus, which produced characteristic colonies readily distinguishable from type 71 staphylococci, was used. Colony counts of each organism, grown alone as well as together in digest broths, were made by the method of Miles \& Misra (1938) on nutrient agar medium. An average of two samples 


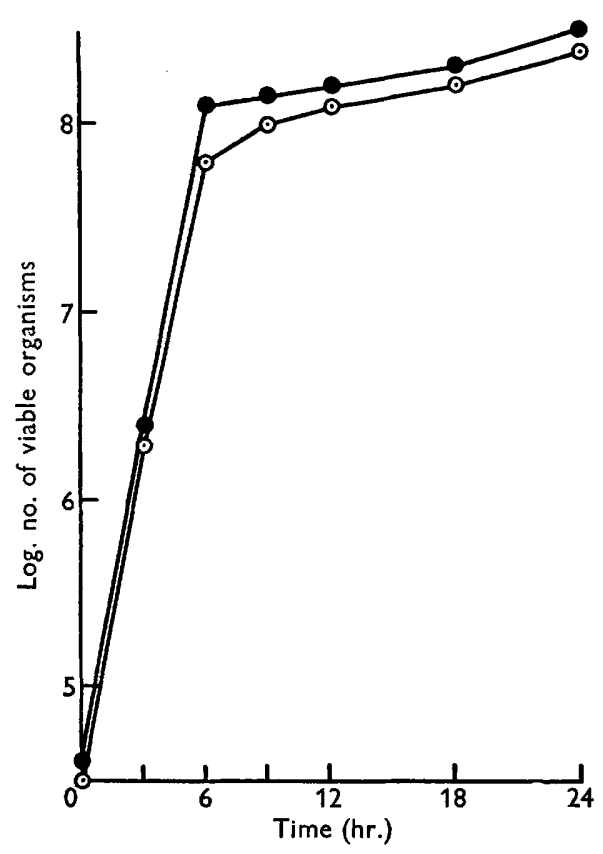

Fig. 1

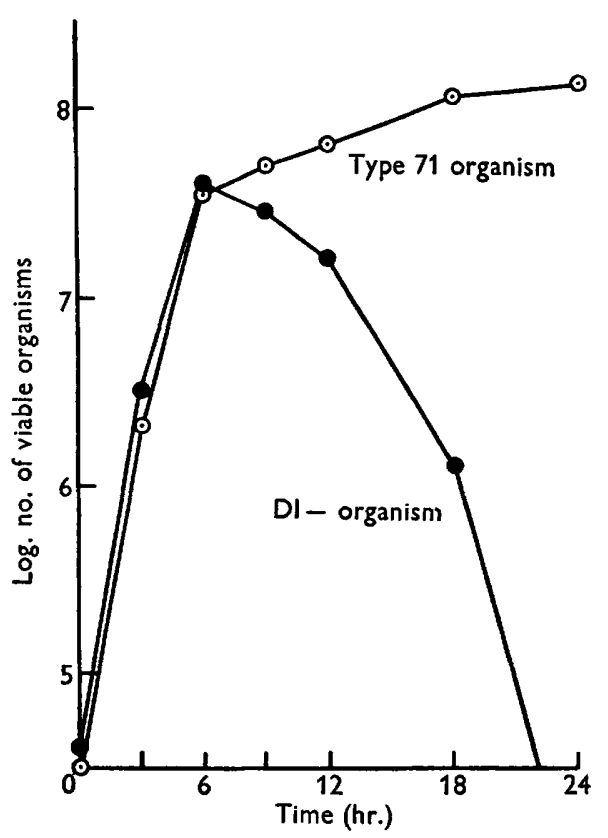

Fig. 2

Fig. 1. Growth of control cultures of non-inhibitory (DI-) and of active (DI +) type 71 strains of Staphylococcus aureus alone in digest broth. Inoculum $0.02 \mathrm{ml} . \times 10^{-1}$ of an overnight broth culture. - -- , Type 71 organisms; $-\longrightarrow, D I-$ organisms.

Fig. 2. Growth of non-inhibitory (DI-) and active (DI +) type 71 Staphylococcus aureus strains together in digest broth. Inoculum $0.02 \mathrm{ml} . \times 10^{-1}$ of an overnight broth culture of each strain. - -- , Type 71 organisms; - - DI- organisms.

Table 1. Inhibition of growth of DI- staphylococci in bacteria-free type 71 antibiotic material by the dilution assay technique

Material dispensed in $1.0 \mathrm{ml}$. amounts

Normal broth

$\begin{array}{ccc} & \text { DI }- & 48 \\ & & 24 \\ \text { Type 71 culture } & \text { Type 71 } & \mathbf{2 4} \\ \text { supernatant } & & 48 \\ & \text { DI }- & 24 \\ & & 48 \\ \text { DI - culture } & \text { Type 71 } & 24 \\ \text { supernatant } & & 48 \\ & \text { DI }- & 24 \\ & & 48\end{array}$

\section{Period}

Staph. of aureus incubation inoculated

(hr.)
Growth from $0 \cdot 02 \mathrm{ml}$. inocula of broth culture dilutions

\begin{tabular}{|c|c|c|c|c|c|}
\hline $10^{-1}$ & $10^{-2}$ & $10^{-3}$ & $10^{-4}$ & $10^{-5}$ & $10^{-6}$ \\
\hline $\begin{array}{l}+++ \\
++t\end{array}$ & $\begin{array}{l}++++ \\
++++\end{array}$ & $\begin{array}{l}++++ \\
++++\end{array}$ & $\begin{array}{l}+++ \\
+++t\end{array}$ & $\begin{array}{l}++++ \\
++++\end{array}$ & $\begin{array}{l}++t \\
++t+\end{array}$ \\
\hline $\begin{array}{l}+++ \\
++++\end{array}$ & $\begin{array}{l}++++ \\
++++\end{array}$ & $\begin{array}{l}++++ \\
++++\end{array}$ & $\begin{array}{l}++++ \\
++++\end{array}$ & $\begin{array}{l}+++ \\
++++\end{array}$ & $\begin{array}{l}+++ \\
++++\end{array}$ \\
\hline $\begin{array}{l}++++ \\
++++ \\
+t\end{array}$ & $\begin{array}{l}++++ \\
++++\end{array}$ & $\begin{array}{l}+++ \\
++++ \\
-\end{array}$ & $\begin{array}{l}++t \\
++++\end{array}$ & $\begin{array}{l}++ \\
++++\end{array}$ & $\begin{array}{l}+ \\
+++\end{array}$ \\
\hline $\begin{array}{l}++ \\
++t\end{array}$ & $\bar{t}++$ & $\bar{t}+$ & $\bar{t}$ & $\overline{ \pm}$ & - \\
\hline $\begin{array}{l}+++ \\
++++\end{array}$ & $\begin{array}{l}+++t \\
+++t\end{array}$ & $\begin{array}{l}++++ \\
++++\end{array}$ & $\begin{array}{l}+++t \\
++++\end{array}$ & $\begin{array}{l}+++ \\
+++t\end{array}$ & $\begin{array}{l}++ \\
++++\end{array}$ \\
\hline $\begin{array}{l}+++ \\
+++t\end{array}$ & $\begin{array}{l}+++t \\
+++t\end{array}$ & $\begin{array}{l}++++ \\
++++\end{array}$ & $\begin{array}{l}+++t \\
++++\end{array}$ & $\begin{array}{l}++t \\
++t+\end{array}$ & $\begin{array}{l}++ \\
++t+\end{array}$ \\
\hline
\end{tabular}

,,,,$+++++++++ \pm=$ arbitrary visual assessment of growth; $-=$ no visible growth. 
was taken for estimation of the numbers of viable organisms. Samples were withdrawn at $3 \mathrm{hr}$. intervals, with as little disturbance of the cultures as possible. Duplicate counts, determined by inhibition of corynebacteria seeded on blood agar medium, were substantially similar.

The results obtained, starting with approximately equal inocula, are shown as growth curves in Figs. 1 and 2. In the mixed culture, each organism multiplied normally during the log phase of growth. Thereafter the numbers of surviving DI staphylococci decreased rapidly as compared with the control culture, whereas growth of the type 71 organisms was unimpaired. In further experiments with different proportions of organisms in the inoculum, the growth of the DI - staphylococci was largely suppressed when they were outnumbered initially by type 71 organisms in a ratio of more than 10:1. Conversely, when DI - organisms were in similar initial excess, their growth was not suppressed by type 71 staphylococci. In no instance was growth of type 71 organisms impaired.

\section{DISCUSSION}

In the present work, different liquid media were found, after growth of type 71 staphylococci, to vary considerably in their ability to yield preparations active in cup assays against indicator corynebacteria. Broth freshly prepared by tryptic digestion of meat was usually satisfactory for this purpose, although deterioration occurred on storage. The inhibitory agent was not, however, extracted from this broth. It remained in solution after the addition of trichloroacetic acid to broth cultures, and some of its properties were investigated after concentrating this material by evaporation. It was stable and relatively heat resistant under acid conditions, inactivated by trypsin but not by pepsin, was readily destroyed when alkaline, and was slowly dialysable. Resistance to heat and rapid passage of the inhibitory agent through similar Visking cellophan was also observed with type 71 cultures on solid media (Barrow, 1963). These properties suggest that it may be a small protein or a polypeptide (Waksman, 1947).

Although inhibitory to corynebacteria, the concentrated broth preparations showed only doubtful activity in cup assays against other staphylococcal strains. Inhibitory activity by type 71 strains, however, was detected in mixed broth cultures against non-inhibitory staphylococci, and was similar to that previously observed on solid media (Barrow, 1963). The type 71 inhibitory substance differs in activity from the agents produced by the two antagonistic NCTC 'aureus' strains; one of these was investigated by Gardner (1949) and the inhibitory agent thought to be a protein. These organisms were used for comparison in the present work, but active bacteria-free preparations were not obtained by the methods described for type 71 organisms. Similar antibiotic substances, thought to be proteins or polypeptides, were obtained in a crude state from staphylococcal cultures by Loeb, Moyer \& Murray (1950) and by Halbert, Swick \& Sonn (1953). Many of these agents differed only in their heat stability or in their specificity of action, and were thus analogous to the colicines produced by enterobacteria (Fredericq, 1957). Numerous bacterial species are now known to produce active metabolites of this kind, but their role in the initiation or in the severity of infections is still uncertain.

I am grateful to Dr H. G. Smith for advice and encouragement during this work. 


\section{REFERENCES}

BARRow, G. I. (1955). Clinical and bacteriological aspects of impetigo contagiosa. $J$. Hyg., Camb. 53, 495.

BARrow, G. I. (1963). Microbial antagonism by Staphylococcus aureus. J. gen. Microbiol. $31,471$.

FredericQ, P. (1957). Colicins. Annu. Rev. Microbiol. $11,7$.

Gardner, J. F. (1949). An antibiotic produced by Staphylococcus aureus. Brit. J. exp. Path. 30, 130.

Halbert, S. P., Swick, L. \& Sonn, C. (1953). Characteristics of antibiotic-producing strains of the ocular bacterial flora. J. Immunol. 70, 400.

Loeb, L. J., Moyer, A. \& Murray, R. G. E. (1950). An antibiotic produced by Micrococcus epidermidis. Canad. J. Res. (E), 28, 212.

Miles, A. A. \& Misra, S. S. (1938). The estimation of the bactericidal power of the blood. J. Hyg., Camb. 38, 732.

Parker, M. T. (1958). Some cultural characteristics of Staphylococcus aureus strains from superficial skin infections. J. Hyg., Camb. 56, 238.

Parker, M. T. \& Simmons, L. E. (1959). The inhibition of Corynebacterium diphtheriae and of other Gram-positive organisms by Staphylococcus aureus. J. gen. Microbiol. 21, 457.

Parker, M. T., Tomlinson, A. J. H. \& Williams, R. E. O. (1955). Impetigo contagiosa. The association of certain types of Staphylococcus aureus and of Streptococcus pyogenes with superficial skin infections. J. Hyg., Camb. 53, 458.

WAKSMan, S. A. (1947). Microbial antagonisms and antibiotic substances, 2nd ed. New York: Commonwealth Fund. 